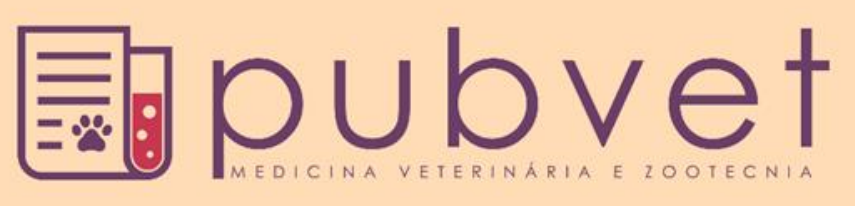

ISSN $1982-1263$

https://doi.org/10.31533/pubvet.v13n6a348.1-9

\title{
Endocardite infecciosa em cães: Revisão
}

\author{
Ludmila de Souza Fernandes Augusto ${ }^{1 \oplus}$, Nathália Marques de Oliveira Lemos ${ }^{2 \ominus}$, Bruno Alberigi ${ }^{3 *}$ \\ ${ }^{I}$ Discente do curso de Medicina Veterinária da Universidade Castelo Branco, Rio de Janeiro - RJ Brasil. \\ ${ }^{2}$ Mestranda no Programa de Pós-Graduação em Medicina Veterinária-Patologia e Ciências Clínicas - da Universidade Federal Rural do \\ Rio de Janeiro, Rio de Janeiro - RJ Brasil. \\ ${ }^{3}$ Professor do curso de Medicina veterinária da Universidade Castelo Branco, Rio de Janeiro - RJ Brasil. \\ *Autor para correspondência, E-mail: bruno.alberigi@castelobranco.br
}

Resumo. A endocardite infecciosa (EI) é uma doença sistêmica causada por colonização bacteriana ou, mais raramente fúngica do endocárdio valvar ou mural. A área mais afetada é normalmente o lado esquerdo do coração, com acometimento da valva mitral, aórtica ou ambas. Dentre os animais mais propensos à infecção encontram-se os de porte médio a grande e machos, além da incidência e prevalência se intensificar com o avançar da idade. Os sinais clínicos são muito inespecíficos em sua grande maioria, o que dificulta ainda mais a suspeita e detecção diagnóstica com a precocidade que a doença em questão demanda, mas o desenvolvimento de um sopro ou alteração deste é um forte indício de endocardite valvar. O diagnóstico se dá principalmente por resultados positivos de hemocultura, com atenção para infecções por microrganismos do gênero Bartonella, que dificilmente se consegue identificar por meio de técnicas microbiológicas padrão e, também por meio da visualização de lesões vegetativas características com auxílio do método ecocardiográfico. O protocolo terapêutico indicado é a base de administração de antimicrobianos bactericidas, que não deve ser postergado e, sempre apoiado nos resultados de hemocultura e antibiograma. O objetivo deste trabalho é realizar uma revisão de literatura sobre EI em cães, com destaque nos principais aspectos clínicos, diagnóstico e tratamento da doença.

Palavras chave: bacteremia, endocárdio, hemocultura, infecção

\section{Infective endocarditis in dogs: Review}

Abstract. Infective endocarditis (IE) is a systemic disease caused by bacterial or, more rarely, fungal colonization of the valvar or mural endocardium. The most affected area is usually the left side of the heart, with involvement of the mitral valve, aortic valve, or both. Among the animals most prone to infection are those of medium to large size and males, in addition to the incidence and prevalence intensified with advancing age. The clinical signs are very unspecific in the majority, which makes it even more difficult to suspect and diagnose the precocity that the disease in question demands, but the development of a murmur or alteration of this is a strong indication of valve endocarditis. The diagnosis is mainly due to positive results of blood culture, with attention to infections by microorganisms of the genus Bartonella, which can hardly be identified through standard microbiological techniques and through the visualization of characteristic vegetative lesions using the echocardiographic method. The indicated therapeutic protocol is the basis for administration of bactericidal antimicrobials, which should not be postponed and always supported in the results of blood culture and antibiogram. The objective of this work is to carry out a literature review on IE in dogs, with emphasis on the main clinical aspects, diagnosis and treatment of the disease.

Keywords: bacteremia, endocarditis, blood culture, infection 


\section{Endocarditis infecciosa en perros: Revisión}

Resumen. La endocarditis infecciosa (EI) es una enfermedad sistémica causada por colonización bacteriana o, más raramente fúngica del endocardio valvular o mural. El área más afectada es normalmente el lado izquierdo del corazón, con la afectación de la válvula mitral, aórtica o ambas. Entre los animales más propensos a la infección se encuentran los de tamaño medio a grande y machos, además de la incidencia y prevalencia se intensifica con el avance de la edad. Los signos clínicos son muy inespecíficos en su gran mayoría, lo que dificulta aún más la sospechosa y detección diagnóstica con la precocidad que la enfermedad en cuestión demanda, pero el desarrollo de un soplo o alteración de éste es un fuerte indicio de endocarditis valvular. El diagnóstico se da principalmente por resultados positivos de hemocultivo, con atención para infecciones por microorganismos del género Bartonella, que difícilmente se puede identificar por medio de técnicas microbiológicas estándar y, también por medio de la visualización de lesiones vegetativas características con auxilio del método ecocardiográfico. El protocolo terapéutico indicado es a base de la administración de antimicrobianos bactericidas, que no debe ser postergado y, siempre apoyado en los resultados de hemocultivo y antibiograma. El objetivo de este trabajo es realizar una revisión de literatura sobre EI en perros, con destaque a los principales aspectos clínicos, diagnóstico y tratamiento de la enfermedad.

Palabras clave: bacteriemia, endocárdica, hemocultivo, infección

\section{Introdução}

A endocardite infecciosa (EI) é um processo patológico sistêmico, caracterizado pela colonização bacteriana ou fúngica do endocárdio valvar ou mural. As quatro valvas cardíacas podem ser acometidas. No entanto, as valvas mitral e aórtica são as mais predispostas (Miller \& Sisson, 1999). Embora apresente baixa prevalência em cães, as taxas de morbidade e mortalidade são elevadas (Miller et al., 2004).

As manifestações clínicas podem advir de quadros subagudos, agudos ou crônicos, cujas principais consequências incluem: insuficiência cardíaca congestiva, tromboembolismo, arritmias e óbito (Barroso et al., 2005; Lemsaddek et al., 2016).

O diagnóstico da EI é desafiador, em função da inespecificidade dos sinais clínicos. A identificação ao exame ecodopplercardiográfico das lesões vegetativas oscilantes nas valvas cardíacas denota a probabilidade da afecção. Contudo, a maioria dos casos somente é identificada na necropsia (Barroso et al., 2005; Miller et al., 2004). A identificação do microrganismo envolvido é de fundamental importância para a instituição do tratamento adequado e elaboração do prognóstico, frente a sua patogenicidade, que de forma geral é desfavorável (Lemsaddek et al., 2016).

O presente trabalho objetiva a revisão de literatura de endocardite infecciosa em cães, discorrendo sobre a epidemiologia, etiologia, fisiopatogenia, sinais clínicos, diagnóstico, tratamento, prevenção e prognóstico.

\section{Epidemiologia}

A prevalência da EI em cães é de 0,11 a 0,58\% (Miller \& Sisson, 1999). Acomete principalmente cães machos, de meia idade a idosos, de médio e grande porte, sendo as raças mais predispostas o pastor alemão, boxer, rotweiller, golden, labrador retriever, setter irlandês e dogue alemão (Barroso et al., 2005; Ware, 2015b).

\section{Etiologia}

A bacteremia, persistente ou transitória, é fator predisponente para o desenvolvimento da EI. O foco infeccioso pode estar presente em diversos órgãos, como: pele, cavidade oral, vias urinárias, próstata e pulmão (Miller \& Sisson, 1999). Os microrganismos infectam as valvas mediante o contato direto com a superfície endotelial, corrente sanguínea ou capilar das mesmas, sendo os principais patógenos: Streptococcus sp., Staphylococcus sp., Escherichia coli, Pseudomonas aeruginosa, Corynebacterium 
spp., Erysipelothrix rhusiopathiae. Salmonella spp., Citrobacter spp. e Mycobacterium spp. (Jericó et al., 2015). Vale ressaltar que a Bartonella spp. foi descrita como ocasionadora da EI no norte da Califórnia, com prevalência de 18 a 28\% (Abbott, 2016; Chomel et al., 2009). Outros fatores que predispõem a EI incluem: doença periodontal, doenças valvares degenerativas, administração indiscriminada de antibióticos e drogas imunossupressoras (Miller \& Sisson, 1999). Os procedimentos odontológicos são questionados consoantes à probabilidade de desenvolvimento da EI, não obstante apresentam elevada prevalência (85\%), sendo o grau da doença periodontal diretamente relacionado a esta probabilidade (Abbott, 2016; Miller et al., 2004).

A administração indiscriminada de antibióticos, bem como o uso de drogas imunossupressoras pode resultar em microrganismos resistentes, predispondo para quadros graves de EI, por isso devem ser utilizados com cautela (Birchard \& Sherding, 2008).

A despeito de lesões valvares predisporem a EI, não há evidencias que a Doença Valvar Degenerativa Crônica de Mitral (DVDCM) seja um fator predisponente (Jericó et al., 2015; Miller et al., 2004). A DVDCM é caracterizada por processo degenerativo mixomatoso, resultando em lesão fibrótica sem comprometimento do endotélio, por conseguinte a superfície é irregular porem integra, sendo, portanto, pouco passível à aderência bacteriana (Reece \& Penteado Júnior, 1996; Zachary et al., 2012).

\section{Fisiopatogenia}

A patogenia da EI decorre da ausência de integridade endotelial, fluxo sanguíneo turbulento, sistema imunológico do cão, virulência e propriedades intrínsecas dos patógenos (Jericó et al., 2015; Miller et al., 2004).

A lesão endotelial oportuniza a formação de agregados de fibrina plaquetária, propiciando um meio susceptível à invasão e colonização bacteriana (Miller et al., 2004). Ressalta-se que há aglomerados de plaquetas estéreis, constituídos de fibrina e glóbulos vermelhos, denominados de endocardite trombótica não bacteriana (ETNB) por Zeiger em 1888, cujo fluxo sanguíneo de alta velocidade preludiam as lesões que se sucedem à insuficiência valvar já existente ou estenose (Miller \& Sisson, 1999). A formação do trombo precede a infecção valvar, consecutiva à bacteremia, ocasionando processo inflamatório variável, resultando em deformação e destruição dos folhetos das valvas, bem como de suas estruturas associadas (Abbott, 2016). A capacidade de adesão dos microrganismos é mensurada por componentes superficiais microbianos que reconhecem moléculas de matriz adesivas (MSCRAMMS - microbial surface components recognizing adhesive matrix molecules), expressa na superfície de algumas bactérias (MacDonald, 2010).

Nas vegetações estabelecidas, as colônias dos microrganismos são protegidas por fibrina, plaqueta e células vermelhas, com pouca presença de granulócitos. Estas vegetações são relativamente avasculares, prejudicando a penetração de anticorpos, células fagocíticas e antibióticos (Miller \& Sisson, 1999) (Figura 1). Pressupõe-se que altos títulos de anticorpos aglutinantes, responsáveis por provocarem agregação bacteriana, maximizem as infecções inoculadas, assumindo um importante papel na patogênese de alguns casos (Birchard \& Sherding, 2008).

A fisiopatogenia da colonização vegetativa é pouco conhecida, porem especula-se que a produção de fibronectina pelas células endoteliais, plaquetas e fibroblastos em resposta à injúria seja importante no processo, frente a maioria dos agentes patogênicos da EI expressarem receptores para esta glicoproteína em suas superfícies. Outro fator importante é o polissacarídeo produzido pelas bactérias denominado dextrana, que facilita sua aderência ao complexo plaqueta-fibrina (Jericó et al., 2015). A intensidade da destruição valvar é variável, consoante à virulência do organismo infectante e o tempo de infecção. A destruição do estroma da valva e cordoalha tendinea acarreta insuficiência da valva e consequentemente insuficiência cardíaca. A extensão da infecção no anel valvar, no seio de Valsalva, pericárdio ou miocárdio culminam na formação de abscessos, pericardite purulenta, miocardite ou destruição do sistema de condução (Miller \& Sisson, 1999). A Figura 2 demonstra resumidamente o mecanismo de invasão e adesão microbiana ao endotélio lesionado. 


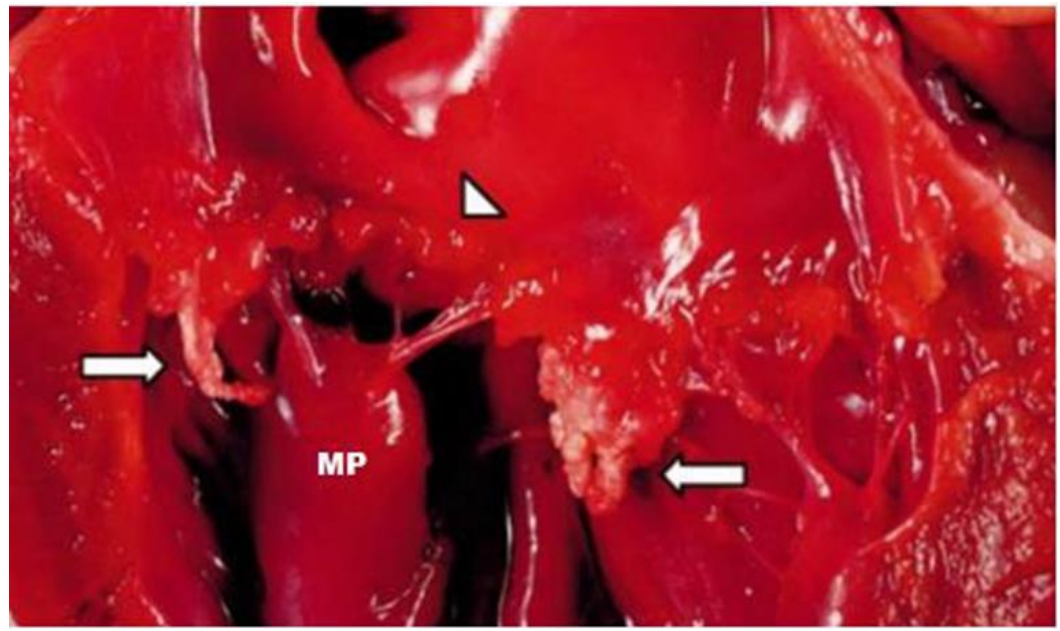

Figura 1. lesões vegetativas com envolvimento dos folhetos anteriores e posteriores da valva mitral (Cabeça de seta $=$ folheto valvar evidenciando lesões vegetativas; setas $=$ lesões vegetativas acometendo folhetos valvares e cordoalhas tendíneas; MP = músculo papilar). Fonte: Tou et al. (2005).

Consequências sistêmicas como: infecções tromboembólicas, arritmias, desordens imuno-mediadas, sepse e Insuficiência Cardíaca Congestiva (ICC), podem advir da EI (Lemsaddek et al., 2016). O aglomerado bacteriano ou coágulo que compõem as lesões vegetativas, podem se desprender e alcançar órgãos alvos com obstrução do fluxo sanguíneo arterial e consequentemente infartos e infecções metastáticas (Barroso et al., 2005; Miller \& Sisson, 1999). Sendo o rim o órgão mais comumente afetado pelo tromboembolismo (Jericó et al., 2015).

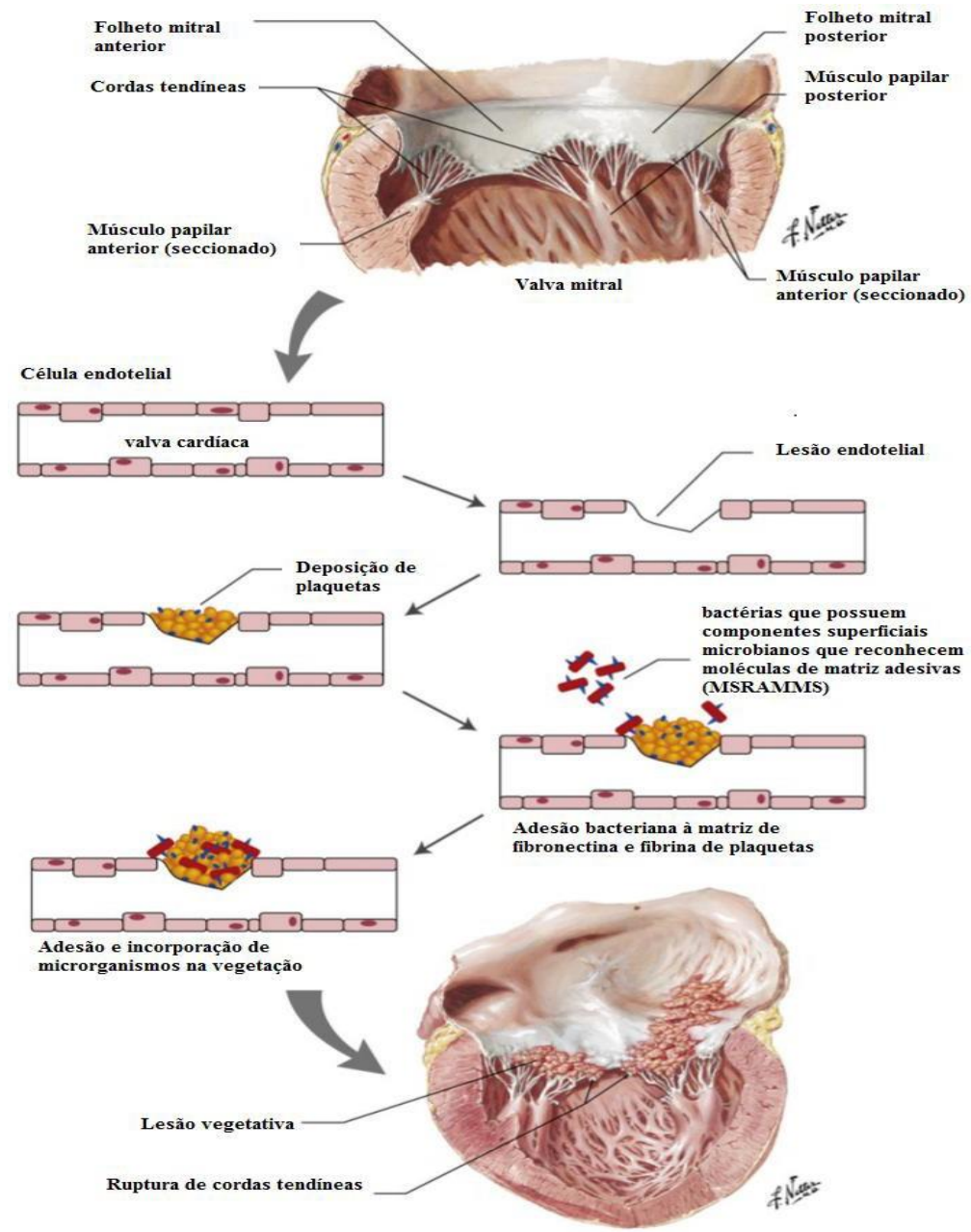

Figura 2. Desenvolvimento de endocardite infecciosa em razão de presença de lesão no endotélio. Fonte: MacDonald (2010). 
As arritmias decorrem da infecção do miocárdio, tromboembolismo, hipóxia miocárdica e da vasculite imunológica mediada que afetam o sistema de condução (Birchard \& Sherding, 2008; Miller et al., 2004).

O incitamento dos sistemas imunológicos humorais e celulares por meio de bacteremia persistente é causador de muitas apresentações extracardíacas. Os anticorpos, o fator reumatóide e os imunocomplexos circulantes são fatores auxiliadores no desenvolvimento de poliartrite, miocardite e glomerulonefrite em cães com EI. A proteinúria sobrevinda da glomerulonefrite ocasiona a perda de antitrombina III e promove um estado hipercoagulável, favorecendo o desenvolvimento de tromboembolismo não bacteriano, bem como novas lesões de EI (Jericó et al., 2015).

A liberação do fator de necrose tumoral alfa (TNF-a) e a interleucina-1 (IL-1) pelos macrófagos, bem como a liberação de outras células inflamatórias oriundas da resposta ao contato com endotoxina bacteriana e seus respectivos componentes e produtos, ativam as células endoteliais e outras células efetoras, como: linfócitos $\mathrm{T}$ e $\mathrm{B}$, macrófagos, monócitos e neutrófilos, induzindo a liberação de mais citocinas inflamatórias, como: IL-6 e IL-8, fator de crescimento transformador beta (TGF- $\beta$ ), prostaglandina (PGE2), fator estimulante de colônias, fator ativador de plaquetas, eicosanoides e mediadores inflamatórios. Esses componentes alteram a fisiologia e estabelecem o fenômeno da sepse (Miller \& Sisson, 1999).

A insuficiência cardíaca congestiva (ICC) é resultante de insuficiência sistólica ou diastólica, sendo a ICC esquerda mais prevalente na EI, devido ao maior acometimento das valvas mitral e aórtica. A redução do volume sistólico advém da diminuição da contratilidade miocárdica (insuficiência miocárdica), sobrecarga volumétrica devido à insuficiência valvar ou desvios sanguíneos e ainda por aumento da pós-carga, dificultando o esvaziamento adequado dos ventrículos. Já a insuficiência miocárdica diastólica provém do relaxamento e da distensibilidade ventriculares inadequados relacionados a danos diretos no musculo cardíaco (Jericó et al., 2015; Reece, 2008).

\section{Sinais clínicos}

Os sinais clínicos tendem a ser inespecíficos, variando conforme o quadro da doença. Em quadros subagudos de EI os sinais clínicos mais comumente observados são: claudicação, inapetência, dispneia, síncope e intolerância ao exercício. Em quadros agudos e crônicos os sinais clínicos de sepse são os mais proeminentes, como: pirexia e choque (Abbott, 2016).

A pirexia é um achado comum em cães com EI, sendo bastante útil na elaboração da suspeita quando associados para outros achados clínicos (Miller \& Sisson, 1999; Ware, 2015b). Todavia, não necessariamente estará presente em todos os animais doentes. Antibióticos, aspirina e corticosteroides, assim como infecções crônicas influem na presença da febre (Abbott, 2016; Miller \& Sisson, 1999).

O sopro à ausculta cardíaca pode ser indício de endocardite valvar. Contudo não é um achado patognomônico da EI, podendo estar relacionado também à insuficiência das valvas por outras afecções, como: doença degenerativa valvar, doenças congênitas, cardiomiopatias ou alterações físicas (Miller et al., 2004; Ware, 2015b). A tosse, dispneia, sons pulmonares anormais, síncope, cianose, ascite, edema de membros e pulso fraco podem ser procedentes da ICC (Abbott, 2016; Ware, 2015a).

No tromboembolismo observam-se pulsos arteriais femorais desiguais ou ausentes, frieza e cianose de extremidades, necrose de pele, além de diversos distúrbios neurológicos em caso de acometimento do sistema nervoso central (Jericó et al., 2015; Miller et al., 2004). Os déficits neurológicos podem estar relacionados também a quadros de meningites ou encefalites em pacientes com EI (Birchard \& Sherding, 2008).

\section{Diagnóstico}

O diagnóstico baseia-se no histórico, anamnese, exames laboratoriais e exames complementares (Miller et al., 2004). No histórico e anamnese é importante averiguar infecções recentes ou em curso, principalmente na cavidade oral, pele, trato intestinal, trato urogenital ou ossos; bem como se o paciente foi submetido a algum procedimento diagnóstico ou terapêutico invasivo, que predispõe a EI por causarem bacteremia, como por exemplo: implantes cirúrgicos, extração dentária e endoscopias. Outro 
fator importante é o uso de corticosteroides, drogas imunossupressoras ou o uso indiscriminado de antibióticos, que também podem favorecer a instalação de EI (Birchard \& Sherding, 2008).

Nos exames laboratoriais, o hemograma pode revelar discreta anemia, trombocitopenia, leucocitose com neutrofilia e monocitose. Fragmentos de eritrócitos podem remeter à vasculite ou coagulação intravascular disseminada (CID) (Barroso et al., 2005; Birchard \& Sherding, 2008). As alterações bioquímicas repercutem o acometimento dos órgãos pela infecção, observando-se frequentemente azotemia; elevação das enzimas hepáticas como: fosfatase alcalina (FA), alamina aminotransferase (ALT) e aspartato aminotransferase (AST); hiperbilirrubinemia; hiperglicemia ou hipoglicemia; e hipoalbuminemia (Birchard \& Sherding, 2008; Jericó et al., 2015).

A hemocultura com resultado positivo é uma forte evidencia de endocardite infecciosa. Devem ser utilizados meios de cultura para bactérias aeróbias e anaeróbias, sendo importante realizar o antibiograma em paralelo (Barroso et al., 2005). Especial atenção deve ser dada a animais que já estejam fazendo uso de antibióticos no momento da cultura de sangue, frente à possibilidade do resultado falso negativo. Outros fatores que influenciam e geram resultados falsos negativos são: bacteremia intermitente, endocardite crônica, endocardite não infecciosa, infecção por microrganismos de crescimentos lentos ou difíceis de serem cultivados, como a Bartonella spp (Jericó et al., 2015).

A urinálise pode ser útil ao diagnóstico, uma vez que os rins são fontes de infecções comuns, primária ou secundária. Os achados comuns são: hematúria, piúria, proteinúria e cilindrúria. Recomenda-se também a urocultura, porém não se deve concluir imediatamente que os organismos detectados na urina sejam os mesmos incriminados na infecção do coração (Birchard \& Sherding, 2008; Ware, 2015b).

Os exames complementares cardiológicos realizados incluem a radiografia torácica, o eletrocardiograma e o ecodopplercardiograma (Miller et al., 2004; Miller \& Sisson, 1999). Na radiografia torácica as principais alterações visualizadas são: aumento da silhueta cardíaca e padrão alveolar sugestivo de edema pulmonar, ambos decorrentes das insuficiências valvares (Miller et al., 2004; Ware, 2015a).

No eletrocardiograma os achados são inespecíficos. Os distúrbios de condução mais frequentes são os complexos atriais e ventriculares prematuros, taquiarritmia paroxística e sustentada, bloqueio do ramo do feixe e bloqueio atrioventricular de primeiro, segundo e terceiro graus (Miller \& Sisson, 1999) (Abbott, 2016; Jericó et al., 2015; Miller \& Sisson, 1999).

O ecodopplercardiograma é peça fundamental no diagnóstico da EI permitindo a visualização das lesões, sejam primárias como a vegetação, ou secundárias a infecção como dissolução ou avulsão de um folheto valvar, dilatação da câmara, falência miocárdica, formação de abscessos, insuficiências valvares, entre outras. A detecção dessas alterações depende do tamanho e da localização das lesões, bem como da resolução da imagem obtida e da habilidade do profissional (Jericó et al., 2015; Miller \& Sisson, 1999; Ware, 2015b). Outros fatores limitantes são o porte do animal, peso corporal e estado clínico do paciente, pois taquipneia, dispneia, taquicardia podem comprometer a visualização da imagem ecocardiográfica. Apesar disso, não se deve descartar o diagnóstico de EI baseado em apenas uma avaliação ecocardiográfica negativa, entretanto, é bastante elevado o valor preditivo negativo de uma ecocardiografia de alta qualidade e normal em pacientes que não possuem detecção de sopro (Miller et al., 2004).

As valvas em estágios iniciais da EI encontram-se espessadas e/ou com aumento da ecogenicidade. Lesões vegetativas surgem como massas densas e irregulares, e em lesões mais crônicas o aumento da ecogenicidade pode resultar em calcificação distrófica, como demonstrada na Figura 3. A valva afetada torna-se insuficiente pela destruição do estroma ou formação da vegetação, que impedem a correta coaptação dos folhetos valvares. O orifício valvar pode ser obstruído pela massa vegetativa, acarretando em estenose funcional. $\mathrm{O}$ auxílio por meio da avaliação com Doppler pode ser de grande valia para confirmação tanto de regurgitação quanto de estenose (Birchard \& Sherding, 2008; Miller \& Sisson, 1999; Ware, 2015b). 


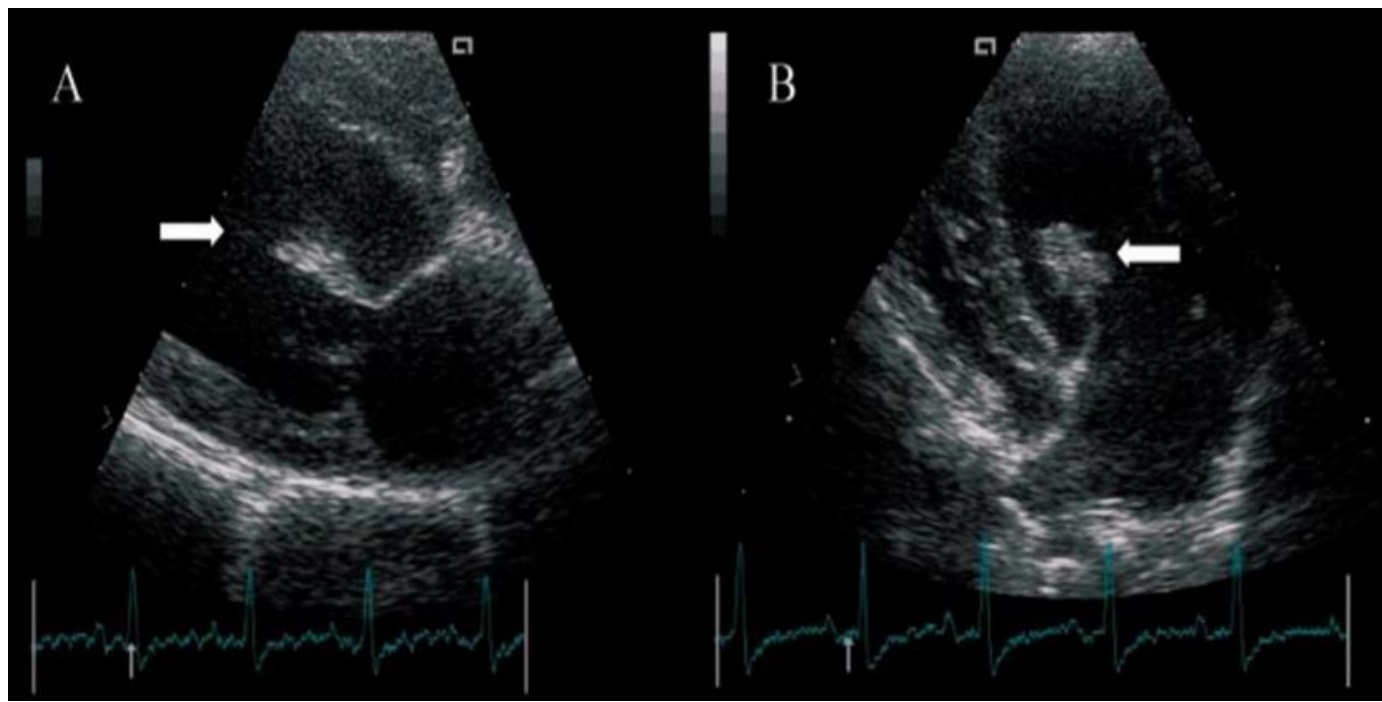

Figura 3. Imagens de ecocardiografia bidimensional de lesão vegetativa hiperecoica na face anterior da valva mitral. Fonte: Tou et al. (2005).

\section{Tratamento}

O tratamento da EI baseia-se na administração de antibiótico. Ocasionalmente é necessário o estabelecimento de protocolos terapêuticos de suporte relacionados as consequências da afecção em associação ao tratamento antimicrobiano (Miller et al., 2004; Miller \& Sisson, 1999). E em alguns casos quando presente a insuficiência cardíaca congestiva deve ser tratada como em outras cardiopatias relacionadas ao aparato valvar (Jericó et al., 2015).

A escolha do antibiótico deve ser embasada nos resultados da cultura e antibiograma. Entretanto o tratamento não deve ser postergado, logo se inicia a terapia empírica com antibióticos de amplo espectro, via endovenosa preferencialmente, utilizando-se as doses máximas preconizadas até a obtenção dos resultados dos exames. Consoante este resultado o tratamento pode ser modificado posteriormente (Barroso et al., 2005; Ware, 2015b). O quadro 1 demonstra a recomendação da classe de antibiótico relacionando com o microrganismo encontrado e a porta de entrada no organismo.

Quadro 1. Escolhas antimicrobianas baseadas no foco infeccioso primário e microrganismos associados para o tratamento de endocardite bacteriana em cães

\begin{tabular}{|l|l|l|l|}
\hline Fonte de bacteremia & Organismos & Primeira escolha & Segunda escolha \\
\hline Piodermite & Staphylococcus spp. & $\begin{array}{l}\text { Cefalosporina de primeira ou segunda } \\
\text { geração; Ticarcilina clavulanada }\end{array}$ & $\begin{array}{l}\text { Aminoglicosídeos; } \\
\text { Fluroquinolonas }\end{array}$ \\
\hline $\begin{array}{l}\text { Trato gastrointestinal, urinário, } \\
\text { peritonite }\end{array}$ & Escherichia coli & $\begin{array}{l}\text { Aminoglicosídeo; Sulfonamida; } \\
\text { Fluroquinolona }\end{array}$ & $\begin{array}{l}\text { Cefalosporina de terceira } \\
\text { geração }\end{array}$ \\
\hline $\begin{array}{l}\text { Trato respiratório, urogenital, } \\
\text { pele }\end{array}$ & $\begin{array}{l}\text { Streptococcus spp. beta-Penicilina; Ticarcilina clavulanada; } \\
\text { hemolítico }\end{array}$ & $\begin{array}{l}\text { Cefalosporina de segunda } \\
\text { geração; Clindamicina }\end{array}$ \\
\hline $\begin{array}{l}\text { Doenças transmitidas por } \\
\text { insetos }\end{array}$ & Bartonella spp. & Doxiciclina & $\begin{array}{l}\text { Azitromicina; } \\
\text { Fluroquinolona }\end{array}$ \\
\hline $\begin{array}{l}\text { Feridas crônicas, queimaduras, } \\
\text { traqueostomia }\end{array}$ & Pseudomonas spp. & Aminoglicosídeo; Fluroquinolona & $\begin{array}{l}\text { Ticarcilina; Cefalosporina de } \\
\text { terceira geração }\end{array}$ \\
\hline $\begin{array}{l}\text { Abscessos, cavidade oral, } \\
\text { microbiota gastrintestinal, } \\
\text { exsudatos das cavidades do corpo }\end{array}$ & Bactérias anaeróbias & $\begin{array}{l}\text { Penicilina; Ticarcilina clavulanada; } \\
\text { Metronidazol; Clindamicina }\end{array}$ & $\begin{array}{l}\text { Ampicilina Clavulanada; } \\
\text { Clorafenicol }\end{array}$ \\
\hline $\begin{array}{l}\text { Pele, membranas mucosas } \\
\text { Corynebacterium spp. } .\end{array}$ & $\begin{array}{l}\text { Penicilina; Ticarcilina clavulanada; } \\
\text { antibióticos macrolídeos }\end{array}$ & Fluroquinolona \\
\hline Cavidade oral & $\begin{array}{l}\text { Erysipelothrix } \\
\text { tonsillarum }\end{array}$ & Penicilina; Cefalosporinas & Eritromicina \\
\hline
\end{tabular}

Fonte: Adaptado de Jericó et al. (2015) 
Na terapia empírica da EI é comum a associação de fármacos, como por exemplo: cefalosporina ou derivado de penicilina sintética (ampicilina: $20-40 \mathrm{mg} / \mathrm{kg}$ TID-QID, ticarcilina: 40-75mg/kg TID-QID, piperacilina: $40 \mathrm{mg} / \mathrm{kg}$ TID) com aminoglicosídeo (gentamicina: 2 a $4 \mathrm{mg} / \mathrm{kg}$ TID, amicacina: $10 \mathrm{mg} / \mathrm{kg}$ TID) ou fluoquinolona (enrofloxacina: $10 \mathrm{mg} / \mathrm{kg}$ BID). Este protocolo abrange a maioria dos microorganismos comumente associados a EI. Em casos de bactérias anaeróbicas, a clindamicina (5$15 \mathrm{mg} / \mathrm{kg}$ SID), o metronidazol (10-15mg/kg TID) ou cefoxitina (25-40mg/kg TID) são os fármacos de eleição (Birchard \& Sherding, 2008; MacDonald, 2010; Miller \& Sisson, 1999; Smarick et al., 2004; Ware, 2015b).

\section{Profilaxia}

A despeito da profilaxia da EI não ser bem definida, o uso profilático de antibióticos é controverso (Birchard \& Sherding, 2008). Pacientes portadores de lesões cardíacas quando submetidos a procedimentos que predispõem a EI, como tratamento periodontal, extração dentária, procedimentos cirúrgicos ou diagnósticos envolvendo trato respiratório, gastrintestinal e urogenital contaminados, são candidatos a receberem antibióticos de forma profilática (Jericó et al., 2015).

Entretanto, especial atenção deve ser dada a alguns fatores no momento da profilaxia, são eles: 1) condição geral do paciente e a probabilidade de desenvolvimento da EI; 2) risco do procedimento ocasionar bacteremia; 3) reações adversas do fármaco a ser administrado; e 4) relação custo benefício da instituição profilática (Barroso et al., 2005).

Preconiza-se a utilização de antibióticos de amplo espectro (cefalosporina, ampicilina, azitromicina), uma a duas horas antes do procedimento, estendendo-se por mais 12 a 24 horas se necessário. Salientase a importância de evitar o uso prolongado, com o intuito de reduzir a possibilidade de resistência microbiana (MacDonald, 2010).

\section{Prognóstico}

O prognóstico da EI é de reservado a desfavorável (Barroso et al., 2005; Birchard \& Sherding, 2008). A doença acarreta em danos irreversíveis nas valvas cardíacas com graves consequências aos animais acometidos (Abbott, 2016). Alguns fatores influenciam negativamente no prognóstico como: infecção por Bartonella spp. ou por gram-negativos, complicações renais ou cardíacas que não sejam responsivas ao tratamento, embolia séptica, trombocitopenia, aumento sérico da fosfatase alcalina, hipoalbuminemia, tratamento com corticosteroides, diagnóstico tardio, tratamento com antibióticos inapropriados e a suspensão terapêutica prematura (Birchard \& Sherding, 2008; Ware, 2015b). Protocolos terapêuticos agressivos e precoces podem favorecer o prognóstico. Igualmente outros fatores que corroboram para um melhor prognóstico incluem: 1) acometimento apenas da valva mitral; 2) infecções por organismos gram-positivos; e 3) endocardite secundária a infecção de pele, abscessos, celulite e feridas (Abbott, 2016; Jericó et al., 2015; Ware, 2015b).

\section{Considerações finais}

A endocardite infecciosa é rara na medicina veterinária. A bacteremia é o fator primordial no estabelecimento da afecção em questão, sendo proveniente de focos infecciosos ou intervenções médicas invasivas. A identificação da endocardite infecciosa é desafiadora frente a ausência de sinais patognomônicos e as limitações diagnósticas. O diagnóstico definitivo deve basear-se nos resultados da hemocultura e antibiograma, todavia são técnicas pouco utilizadas na rotina da medicina veterinária e deveriam ser realizadas com maior frequência. Apesar de o exame ecodopplercardiográfico auxiliar no diagnóstico pela visualização das alterações vegetativas oscilantes características nas valvas cardíacas, há limitações e não se deve desconsiderar a doença com base em apenas uma avaliação ecodopplercardiográfica negativa, sendo recomendadas avaliações seriadas.

A terapia baseia-se na utilização de antibióticos de amplo espectro, instituídos de forma agressiva e precoce de acordo com o microrganismo identificado e o resultado do antibiograma.

O prognóstico é de reservado a desfavorável, com o desenvolvimento de danos irreversíveis as valvas cardíacas e risco de óbito, mediante as graves consequências sistêmicas. 


\section{Referências bibliográficas}

Abbott, J. A. (2016). Infective Endocarditis. In F. W. K. Smith, L. P. Tilley, M. A. Oyama \& M. M. Sleeper (Eds.), Manual of canine and feline cardiology. Elsevier, China, Ásia. China, Ásia: Elsevier.

Barroso, R. M. V., Paula, T. M. \& R., Á. J. (2005). Endocardite BacterianaRevista Eletrônica de Veterinária, VI, 3. Revista Eletrônica de Veterinária, 4(3):1-5.

Birchard, S. J. \& Sherding, R. G. (2008). Manual Saunders: clínica de pequenos animais (Vol. 3). São Paulo.

Chomel, B. B., Kasten, R. W., Williams, C., Wey, A. C., Henn, J. B., Maggi, R., . . Maillard, R. (2009). Bartonella endocarditis: a pathology shared by animal reservoirs and patients. Annals of the New York Academy of Sciences, 1166(1):120-126.

Jericó, M. M., Kogika, M. M. \& Andrade Neto, J. P. (2015). Tratado de medicina interna de cães e gatos. Rio de Janeiro, Brasil: Guanabara Koogan.

Lemsaddek, T. S., Tavares, M., São Braz, B., Tavares, L. \& Oliveira, M. (2016). Enterococcal infective endocarditis following periodontal disease in dogs. PloS One, 11(1):e0146860.

MacDonald, K. (2010). Infective endocarditis in dogs: diagnosis and therapy. Veterinary Clinics: Small Animal Practice, 40(4):665-684.

Miller, M. W., Fox, P. R. \& Saunders, A. B. (2004). Pathologic and clinical features of infectious endocarditis. Journal of Veterinary Cardiology, 6(2):35-43.

Miller, M. W. \& Sisson, D. (1999). Infectious endocarditis. In P. R. Fox, N. S. Moïse \& D. Sisson (Eds.), Textbook of canine and feline cardiology: Principles and clinical practice. Pennsylvania, EUA: W. B. Saunders Company.

Reece, W. O. (2008). Anatomia funcional e fisiologia dos animais domésticos. São Paulo: Editora Roca.

Reece, W. O. \& Penteado Júnior, N. (1996). Fisiologia de animais domésticos. São Paulo: Roca.

Smarick, S. D., Jandrey, K. E., Chomel, B. B., Thomas, W. P. \& Aldrich, J. (2004). Aortic valvular endocarditis caused by Bartonella vinsonii subsp. berkhoffii in 2 dogs presenting for fulminant pulmonary edema. Journal of Veterinary Emergency and Critical Care, 14(1):42-51.

Tou, S. P., Adin, D. B. \& Castleman, W. L. (2005). Mitral valve endocarditis after dental prophylaxis in a dog. Journal of Veterinary Internal Medicine, 19(2):268-270.

Ware, W. A. (2015a). Abordagem terapêutica da insuficiência cardíaca. In R. W. Nelson \& C. G. Couto (Eds.), Medicina interna de pequenos Animais. Rio de Janeiro, Brasil.: Elservier.

Ware, W. A. (2015b). Doenças valvulares e endocárdicas adquiridas. In R. W. Nelson \& C. G. Couto (Eds.), Medicina interna de pequenos Animais. Rio de Janeiro, Brasil.: Elservier.

Zachary, J. F., McGavin, D. \& McGavin, M. D. (2012). Bases da patologia em veterinária. Rio de Janeiro: Elsevier Brasil.

Recebido: 28 de abril, 2019.

Aprovado: 25 de maio, 2019.

Publicado: 25 de junho, 2019.

Licenciamento: Este artigo é publicado na modalidade Acesso Aberto sob a licença Creative Commons Atribuição 4.0 (CCBY 4.0), a qual permite uso irrestrito, distribuição, reprodução em qualquer meio, desde que o autor e a fonte sejam devidamente creditados. 